\title{
Physical activity, self-efficacy, and quality of life in older Czech adults
}

\author{
Jiri Mudrak $^{1} \cdot$ Jan Stochl $^{1,2} \cdot$ Pavel Slepicka $^{1} \cdot$ Steriani Elavsky $^{3}$
}

Published online: 23 August 2015

(C) Springer-Verlag Berlin Heidelberg 2015

\begin{abstract}
Despite efforts to expand global physical activity (PA) surveillance data to include both low- and high-income countries worldwide, our understanding of the relationship between PA and quality of life (QOL) in older adults from culturally diverse backgrounds is limited. We tested McAuley's social-cognitive model of the PA-QOL relationship in the cultural context of the Czech Republic, a post-communist central European country. A total of 546 older Czech adults (mean age 68 years) completed a battery of questionnaires assessing indicators of PA, self-efficacy, health status, and global QOL. A structural equation model was used to test the relationship between PA and QOL. The model hypothesized an indirect relationship between PA and QOL: PA predicted self-efficacy, which in turn predicted global QOL through mental and physical health status. The analyses indicated an acceptable fit of the proposed model, albeit with different emphases than those of studies from Western countries. Above all, we observed a stronger effect of PA on self-efficacy and a weaker mediating effect of health status on the PA-QOL relationship. Our findings supported the validity of McAuley's PA-QOL social-cognitive model for a non-Western cultural context. However, it seems that self-efficacy and
\end{abstract}

Responsible editor: D.J.H. Deeg.

Jiri Mudrak

mudr.ak@post.cz; mudrak@ftvs.cuni.cz

1 Faculty of Physical Education and Sport, Charles University in Prague, Jose Martiho 31, 16252 Prague, Czech Republic

2 Department of Health Sciences, University of York, York, UK

3 Department of Kinesiology, The Pennsylvania State University, University Park, PA, USA health status may influence the PA-QOL relationship in this population in a manner different from that proposed in McAuley's model.

Keywords Physical activity $\cdot$ Older adults $\cdot$ Selfefficacy · Quality of life · Health status · Social cognitive · Structural equation modeling

\section{Introduction}

Regular physical activity (PA) is considered a key to successful and healthy aging with documented benefits for physiological and mental functioning and quality of life (QOL) in older adults (Fox 1999; Kramer et al. 2003; Laurin et al. 2001; Leveille et al. 1999; Netz et al. 2005; U.S. Department of Health and Human Services 2008). Regular PA in older individuals has been linked to a lower occurrence of various diseases, including heart diseases, stroke, diabetes, osteoporosis, or cancer (Nelson et al. 2007); lower risk of injury resulting from falls (Paterson and Warburton 2010); lower risk of disability (Leveille et al. 1999), including cognitive impairment and Alzheimer's disease (Laurin et al. 2001); and higher perceived health and subjective well-being (Netz et al. 2005; Ruuskanen and Ruoppila 1995).

Examining the PA-QOL relationship in older adults, a study by Motl and McAuley 2010 has proposed several conceptualizations of QOL that consider objective as well as subjective factors related to functioning in older age (Motl and McAuley 2010). Generally, QOL has been conceptualized as "subjective well-being or judgments regarding overall satisfaction with life" (Motl and McAuley 2010, $\mathrm{p}$ 304). In this way, QOL conceptually differs from healthrelated quality of life (HRQOL) that encompasses various 
aspects of physical and mental health (Motl and McAuley 2010). Therefore, QOL and HRQOL represent two distinctive yet interrelated constructs. It has been argued that these constructs are hierarchically related to PA with proximal HRQOL (often represented by indices of physical and mental health status) predicting distal QOL (i.e., satisfaction with life) (Elavsky et al. 2005; Motl and McAuley 2010). Similar to other studies on the PA-QOL relationship (McAuley et al. 2006, 2008), in this study, we conceptualized global QOL as a general satisfaction with life.

An additional explanation of the PA-QOL relationship has been provided in the theoretical framework of the social cognitive theory (Bandura 1997). According to this perspective, human behavior and its outcomes are determined by reciprocal interactions between individuals and their environment that are shaped by the ways in which the individuals perceive themselves and their surroundings. Most importantly, the reciprocal individual-environment relationship is moderated by perceived selfefficacy, i.e., a set of task-specific beliefs regarding a perceived capability to successfully accomplish an activity or achieve expected outcomes. This core construct of social cognitive theory has been found to have a pervasive impact on all areas of human functioning (Bandura 1997), including the ways in which PA influences QOL in older adults. Other mediating cognitive factors include outcome expectations, perceived social support, or self-regulation (Bandura 1997; McAuley et al. 2003, 2006, 2011). There have been numerous attempts to explain the nature of the relationship between PA and QOL in older adults by considering self-efficacy and other social-cognitive variables (McAuley et al. 2008; Rejeski and Mihalko 2001; White et al. 2009). It has been shown that self-efficacy is both a determinant and a consequence of PA and is also a mediator of the relationship between PA and various aspects of QOL, including physical and mental health status and satisfaction with life (McAuley et al. 2006, 2008; McAuley and Morris 2007).

However, although important strides have been made in understanding PA and mediating social-cognitive influences on QOL in older adults, the literature remains dominated by data on North American or Western European populations, and our understanding of the relationship between PA and QOL in older people from culturally diverse backgrounds, including the post-communist countries of Central Europe, remains limited. Understanding the nature of the PA-QOL relationship is crucial for successfully implementing health policies, programs, and intervention strategies that aim to improve the life conditions of older people (Nelson et al. 2007). Therefore, it is of interest to know how PA-QOL relationships apply in the context of post-communist European countries where PA-related intervention practices aimed at the older generation have emerged only recently and are relatively underdeveloped (Bauman et al. 2008).

In the past two decades, the post-communist countries of Central Europe have undergone a period of extensive social change. This change has impacted the lives of these countries' citizens in all domains including health-related behaviors, such as PA (Spacek 2009). Significant development can be observed in recent trends in public discourse toward "active aging," emphasizing productivity and activity (including PA) in older age (Hasmanova Marhankova 2010). Simultaneously, the translation of these concepts into practices and policies is still in the initial stages in the Czech Republic and other post-communist countries (Bauman et al. 2008). Contemporary older Czech adults have acquired their PA- or health-related habits, norms, and beliefs in communist Czechoslovakia, i.e., in a different cultural context than that of older adults from Western European and North American countries where the idea of "active" or "successful" aging has been well established (Havighurst 1961; Rowe and Kahn 1997).

Recent studies have suggested that there are notable cultural specificities, related to PA, in the lifestyles of older people in post-communist countries. In the Czech Republic, older age has been traditionally considered to be a period of "well-deserved rest" during which people should cease most of their previous activity (Rabusic 1998). At the same time, however, many Czech seniors provide economic or other support for their children's families. Such support often demands a significant amount of work-related PA and determines the individual's lifestyle after retirement. This work-related PA may include part-time paid work and various non-paid activities, such as household maintenance, gardening, or taking care of grandchildren (Rabusic 1998). In general, older Czech adults may be characterized by a low preference for organized PA, low participation in sports, and high participation in nonsporting PA (Mudrak et al. 2012; Vohralikova and Rabusic 2004). It has been reported that older Czech adults exercise significantly less than their Western counterparts (Laaksonen et al. 2001) with only $12 \%$ of older Czech adults participating in sports or exercise activities (Zavazalova 2001). On the other hand, studies have reported that $70 \%$ of Czech retirees aimed to improve their life by participating in the work-related PA that provides them and their families with additional sources of income and other benefits (Vohralikova and Rabusic 2004).

There also seem to be notable cultural differences in the ways in which people from Western and post-communist countries experience various aspects of their health and its impact on QOL. Most importantly, older adults from postcommunist countries consistently give lower ratings to their physiological and mental health than do older adults in Western countries (Bobak et al. 2000; Carlson 1998, 
2004; Dragomirecka et al. 2008; Eikemo et al. 2008; Laaksonen et al. 2001; Vuorisalmi et al. 2008). These differences have been explained, for example, by broad socioeconomic factors (Bobak et al. 2000; Carlson 1998; Eikemo et al. 2008) or behavioral variables, such as exercise or nutritional behavior (Laaksonen et al. 2001); however, there is lack of a more detailed analysis of the ways in which behavioral variables (such as PA) and psychological variables (such as self-efficacy) interact in producing various QOL outcomes in older adults from post-communist countries. The potential differences in PA-QOL dynamics in older Czech and US adults have also been suggested by our recent comparative study (Mudrak et al. 2012) in which we found that the older Czech adults reported significantly higher (predominantly work-related) PA but significantly lower PA-related self-efficacy and rated their health to be significantly worse than older US adults (Mudrak et al. 2012; Elavsky et al. 2012).

In the present study, we aimed to examine the ways in which PA and PA self-efficacy interact in producing QOLrelated outcomes. We adopted the social-cognitive PAQOL model proposed by McAuley in which PA directly affects PA self-efficacy, which in turn influences HRQOL (i.e., physical and mental health status) and in this way global QOL (as represented by satisfaction with life) (McAuley et al. 2006, 2008; McAuley and Morris 2007). We empirically tested this social-cognitive PA-QOL model in a sample of older Czech adults. We examined whether the proposed relationship between PA and QOL mediated by PA self-efficacy and physical and mental health status was applicable in the post-communist cultural and social context of the Czech Republic.

\section{Materials and methods}

\section{Procedure}

Initially, 700 older Czech adults (aged $\geq 60$ years) from all regions of the Czech Republic were approached; 546 persons (response rate, $71.4 \%$ ) agreed to participate in the study. In the majority of the demographic characteristics, our sample was comparable to the general Czech population of older adults (for a detailed description of the sample, see Results, Table 1). At the same time, the participants were recruited from various Czech organizations for older adults, such as "Universities of the Third Age" or Seniors' Clubs and, therefore, they represented a well-educated sub-population of older Czech adults. Additionally, the older men were considerably less present in these organizations, a fact that negatively affected the gender balance in our sample. We compared the demographical data of our participants to a representative survey conducted in a similar educational organization (a "University of the Third Age," $n=751$ ) (Masaryk University 2011). This survey showed analogous overrepresentation of women and well-educated individuals. Therefore, we assumed that our sample represented this sub-population of older Czech adults.

Upon initial contact made through the official channels of the organizations, the respondents were asked to complete a battery of questionnaires that covered the factors proposed in the social-cognitive model of PA-QOL relationship (McAuley et al. 2006, 2008). Specifically, we included two self-report measures of PA, two measures of PA self-efficacy, two sub-component measures of HRQOL, and a measure of global QOL, complemented by demographic questions. For the purpose of our study, the questionnaires were translated from English by a professional translator, revised by the authors of the study, and backtranslated by another professional translator to verify the accuracy of the translation. The quality of the back-translation (i.e., the similarity between both English versions) was evaluated by a native speaker, an expert in the field of health psychology who uses the original versions of the scales in her research.

\section{Measures}

\section{Physical activity}

PA was assessed using two self-report measures, the Leisure Time Exercise Questionnaire (LTEQ) (Godin and Shephard 1985) and the PA Survey for the Elderly (PASE) (Washburn et al. 1993). The LTEQ measures the self-reported average weekly amount of PA over the previous 4 weeks at three intensity levels (strenuous, moderate, and light) including the time spent sitting. In the LTEQ scoring, the weekly frequencies of strenuous, moderate, and light PA are multiplied by 9,5 , and 3 , and the final score is calculated as the sum of these components. Generally, the individuals scoring $\geq 24$ in the LTEQ are considered to be "active" (Godin and Shephard 1985). The LTEQ is considered to be a valid and reliable instrument for measuring leisure-time PA and has been previously used with older adults (Godin and Shephard 1985; Kliman and Rhodes 2008).

The PASE records PA levels in various domains (household, work, and leisure), types of PA (such as walking, leisure activities, exercise, household chores, or work-related PA), and perceived intensity of PA (light, moderate, strenuous PA, and time spent sitting) as performed in the last week. The PASE scores range from 0 to 361 with the higher scores indicating a higher level of PA. A PASE validation study (Washburn et al. 1999) found that on average, people aged 55-64 years scored 144.2 
Table 1 Demographical characteristics of the sample

\begin{tabular}{lll}
\hline Age & Mean (SD) & $68.0(6.26)$ \\
\hline Gender & Females & $79.2 \%$ \\
& Males & $20.8 \%$ \\
Education & Elementary & $11.6 \%$ \\
& High school & $57.6 \%$ \\
& University & $30.7 \%$ \\
Monthly household income & $<1$ & $12.1 \%$ \\
(compared to the Czech average & $1-1.5$ & $34.3 \%$ \\
per capita income for people & $1.5-2$ & $17.2 \%$ \\
aged $\geq 60$ years) & $2-2.5$ & $18.4 \%$ \\
& $>2.5$ & $18.0 \%$ \\
Physically active (according to & & $51.9 \%$ \\
WHO) & & $27.21(9.20)$ \\
BMI & Mean (SD) & $54.2 \%$ \\
Marital status & Married/living & $26.4 \%$ \\
& with a partner & $13.4 \%$ \\
& Widowed & $4.5 \%$ \\
Number of children & Divorced/separated & $1.88(0.77)$ \\
\hline
\end{tabular}

$(\mathrm{SD}=75.8)$ and people aged $>65$ years scored 118.9 $(\mathrm{SD}=63.9)$. Compared to the LTEQ, the PASE covers a broader range of PA focusing on PA at work and in the home. The PASE, designed specifically for older adults, is considered to be a valid instrument for measuring PA in this age group (Washburn et al. 1993).

\section{Self-efficacy measures}

Two scales were used to measure PA self-efficacy. The Lifestyle PA Self-Efficacy (LPASE) scale (Elavsky and McAuley 2007) is a modified version of the Exercise SelfEfficacy Scale (McAuley 1992) and assesses the participants' beliefs in their ability to continue accumulated moderate intensity PA five or more days per week for $\geq 30$ min per day over the subsequent 6 months. The Barrier Self-Efficacy (BASE) scale (McAuley 1992) measures the extent to which the respondents believe that they will participate in sufficient PA (i.e., at least five times a week, 30 min per session) over the next 6 months even if they encounter obstacles (such as bad weather, time constraints, motivational problems, or insufficient social support). The LPASE and the BASE are scored in a similar way. For each item, the participants indicated their confidence with regard to executing the behavior using a 100 -point percentage scale comprising 10-point increments, ranging from $0 \%$ (not at all confident) to $100 \%$ (highly confident). A self-efficacy score was calculated as a mean score of all of the items.

\section{Health-related and global quality of life measures}

To measure health-related quality of life, we used the 12-item questionnaire SF-12 (Ware et al. 1996). This questionnaire focuses on the self-evaluation of health, perceived health limits, and physical, emotional, and social aspects of health, based on which it provides scores of mental health status (MHS) and physical health status (PHS). The SF-12 is a valid and reliable method for evaluating health frequently used in research on older adults (Ware et al. 1996). The Satisfaction with Life Questionnaire (SWLQ) (Diener et al. 1985) is a 5-item instrument that has been frequently used as an indicator of global QOL (McAuley et al. 2006, 2008; Motl and McAuley 2010). In the SWLQ, the respondents estimate their overall satisfaction with their current conditions and life in general using a 7-point Likert scale ranging from 1 (strongly disagree) to 7 (strongly agree). The SWLQ represents an instrument with good reliability and validity that is suitable for research on older adults (Diener et al. 1985; Rejeski and Mihalko 2001; McAuley et al. 2006).

\section{Data analysis}

In this study, McAuley's social-cognitive PA-QOL model (McAuley et al. 2006, 2008) has been empirically tested within the structural equation modeling (SEM) framework, using a statistical open source software R (R Development Core Team 2014) and lavaan, an $R$ structural equation modeling package (Rosseel 2012). To eliminate the specificity and measurement error of the single measures of PA and self-efficacy, we treat these constructs as latent factors. Therefore, the measurement portion of the model consists of two latent variables: PA, measured by two continuous factor indicators (LTEQ and PASE scores); and self-efficacy, measured by two continuous factor indicators (LPASE and BASE scores). The structural portion of the model describes the hypothesized relationships among PA, self-efficacy, PHS, MHS, and satisfaction with life through the effects of PA on self-efficacy, the effects of self-efficacy on MHS and PHS, and the effects of MHS and PHS on satisfaction with life. The indirect effects were calculated within the context of the structural model, where the indirect effects were estimated automatically. Given the continuous measurement scale of included indicators and their multivariate non-normality ( $p<0.001$ for both Mardia's skew and kurtosis), robust maximum likelihood estimation was used. The missing data appeared to have been missing at random and, therefore, did not systematically bias the model estimates. No outliers were identified in the data. All of the reported coefficients from our analyses are standardized. 
The model fit was assessed using the standard measures of model fit: the $\chi^{2}$ statistic and corresponding $p$ value; the standardized root mean square residual (SRMR), which should approximate or be $<0.08$ for a good fitting model (Bollen 1989; Hu and Bentler 1999); the root mean square error of approximation (RMSEA), with values approximating $\leq 0.05$ being indicative of a close fit and values of $\leq 0.08$ for a good fit) (Browne and Cudeck 1993; MacCallum et al. 1996); and the comparative fit index (CFI values should be higher than 0.90 for adequately fitting solutions) (Marsh et al. 2004). Additionally, we provided measures of relative fit, Akaike Information Criterion (AIC) and Bayesian Information Criterion (BIC) and the $\chi^{2}$ square difference test, which allowed us to compare models with different numbers of parameters.

\section{Results}

\section{Demographic characteristics}

The demographic characteristics of our sample are provided in Table 1. The average age of the participants was 68 years $(\mathrm{SD}=6.26)$. The sample composition reflects the sub-population from which it was drawn (i.e., members of various organizations for older adults) that in several ways differs from the general Czech population of older adults. The most important difference is the over-representation of women $(79.2 \%)$ in our sample. Furthermore, our participants reported higher levels of education than the Czech average for this age group (11.6\% elementary education, $57.6 \%$ high school education, and $30.7 \%$ university education). To estimate how the education level of our sample differs from that of the general Czech population of older adults, the data may be compared to a large representative study from the Czech Statistical Office, which found that $24 \%$ of older Czech adults ( $\geq 65$ years) had elementary education, $56.1 \%$ had high school education, and $9.9 \%$ had university education. The educational level of our sample appeared to reflect more closely the sub-population of economically active older Czech adults, of which $7 \%$ had elementary education, $53 \%$ had high school education, and $31 \%$ had university education (Czech Statistical Office 2011).

In demographic variables, such as income, marital status, or number of children, our sample appeared to be comparable to the general population of older Czech adults (Czech Statistical Office 2011). On the basis of the PA selfreports, $51.9 \%$ of the respondents could be considered to be physically active according to the World Health Organization (WHO) criteria (i.e., participating in at least 150 min of moderate PA per week), which corresponds to the findings of a representative study of older Czech adults in which the criteria for moderate PA were fulfilled by $52.5 \%$ of the sample (Pelcova et al. 2008).

\section{Descriptive statistics}

The mean scores and the standard deviations of the measures included in the analysis are provided in Table 2. Compared with similar data obtained from the samples of older US adults (McAuley et al. 2006, 2008), our sample was characterized by comparable mean scores of PA and lower mean scores of self-efficacy and QOL measures (compare Elavsky et al. 2012; McAuley et al. 2006, 2008; Mudrak et al. 2012, see Tables 2 and 3). The correlation matrix of observed variables is presented in Table 2. Nearly all of the correlations (except LPASE-PHS) were statistically significant and low in magnitude.

\section{Testing the social-cognitive PA-QOL model}

We tested two social-cognitive models of the PA-QOL relationship. First, we tested a social-cognitive model in which the self-efficacy-global QOL relationship was fully
Table 2 Correlations and descriptive statistics of researched variables

\begin{tabular}{llllllll}
\hline & PASE & LTEQ & LPASE & BASE & PHS & MHS & SWL \\
\hline PASE & - & & & & & \\
LTEQ & $0.241^{\mathrm{b}}$ & - & & & & \\
LPASE & $0.234^{\mathrm{b}}$ & $0.284^{\mathrm{b}}$ & - & & & \\
BASE & $0.182^{\mathrm{b}}$ & $0.201^{\mathrm{b}}$ & $0.409^{\mathrm{b}}$ & - & & \\
PHS & $0.131^{\mathrm{b}}$ & $0.208^{\mathrm{b}}$ & 0.051 & $0.098^{\mathrm{a}}$ & - & & \\
MHS & $0.097^{\mathrm{a}}$ & $0.136^{\mathrm{b}}$ & $0.158^{\mathrm{b}}$ & $0.150^{\mathrm{b}}$ & $0.186^{\mathrm{b}}$ & - & \\
SWL & $0.216^{\mathrm{b}}$ & $0.151^{\mathrm{b}}$ & $0.183^{\mathrm{b}}$ & $0.144^{\mathrm{b}}$ & $0.203^{\mathrm{b}}$ & $0.335^{\mathrm{b}}$ & - \\
Mean & 159.0 & 29.8 & 64.6 & 42.8 & 51.1 & 43.6 & 4.7 \\
SD & 74.2 & 22.2 & 33.6 & 23.9 & 9.7 & 9.1 & 1.0 \\
$\%$ missing & 0.4 & 8.1 & 7.3 & 15.0 & 0 & 0 & 4.6 \\
\hline
\end{tabular}

a Correlation is significant at the 0.05 level

b Correlation is significant at the 0.01 level 
Table 3 Researched variables in US samples

\begin{tabular}{|c|c|c|c|c|c|c|c|c|}
\hline & \multicolumn{2}{|c|}{$\begin{array}{l}\text { McAuley et al. (2006) (Older } \\
\text { US women) }\end{array}$} & \multicolumn{2}{|c|}{$\begin{array}{l}\text { McAuley et al. (2008) (Older } \\
\text { US women) }\end{array}$} & \multicolumn{2}{|c|}{$\begin{array}{l}\text { Elavsky et al. (2012) (Older } \\
\text { US adults) }\end{array}$} & \multicolumn{2}{|c|}{$\begin{array}{l}\text { Motl and McAuley (2010) } \\
\text { (US adults with multiple } \\
\text { sclerosis) }\end{array}$} \\
\hline & Mean & SD & Mean & SD & Mean & SD & Mean & SD \\
\hline PASE & 156.6 & 70.6 & 159.1 & 68.1 & 126.8 & 63.0 & - & - \\
\hline LTEQ & - & - & - & - & - & - & 26.5 & 22.4 \\
\hline LPASE & 80.9 & 28.1 & - & - & 80.1 & 27.5 & - & - \\
\hline BASE & - & - & - & - & 55.3 & 23.1 & - & - \\
\hline SF-12 MHS & 52.8 & 8.7 & 53.2 & 8.7 & 55.0 & 6.8 & - & - \\
\hline SF-12 PHS & 47.1 & 9.8 & 47.6 & 9.7 & 45.9 & 8.8 & - & - \\
\hline SWL & 5.1 & 1.6 & 5.2 & 1.2 & 5.4 & 1.2 & 4.36 & 1.6 \\
\hline
\end{tabular}

Table 4 Fit indices and explained variance of the tested models

\begin{tabular}{lll}
\hline Fit indices & Fully mediated model & Partially mediated model \\
\hline SRMR & 0.053 & 0.040 \\
RMSEA & 0.078 & 0.066 \\
CFI & 0.877 & 0.919 \\
AIC & 29368 & 29355 \\
BIC & 29467 & 29458 \\
R2 (SWL) & 0.130 & 0.176 \\
\hline
\end{tabular}

mediated by physical and mental health status. However, we found that the model did not fit well to the data $\left(\chi^{2}=51.576\right.$, $d f=12, p=0.000 ;$ SRMR $=0.053$, RMSEA $=0.078$; $\mathrm{CFI}=0.877, \mathrm{AIC}=29367, \mathrm{BIC}=29466)$. Subsequently, we tested a model in which the self-efficacy-global QOL relationship was only partially, mediated by physical and mental health status. The partially mediated social-cognitive model showed a more acceptable fit to the data $\left(\chi^{2}=36.975, \quad d f=11, \quad p=0.000 ; \quad\right.$ SRMR $=0.040$, RMSEA $=0.066 ; \quad$ CFI $=0.919, \quad$ AIC $=29355$, BIC $=29458)($ Table 4$)$, although the $\chi^{2}$ in this model remained statistically significant. The difference in the model fit between these models was found to be statistically significant $\left(\chi^{2}\right.$ difference $\left.=14.601, d f=1, p<0.001\right)$.

Within the partially mediated model, the higher levels of $\mathrm{PA}(\beta=0.808 ; \mathrm{SE}=0.099)$ positively predicted the higher level of self-efficacy, which predicted the mental health status $(\beta=0.294 ; \mathrm{SE}=0.052)$, physical health status $(\beta=0.214 ; \quad \mathrm{SE}=0.065)$, and satisfaction with life $(\beta=0.221 ; \quad \mathrm{SE}=0.060) . \quad$ Physical health status $(\beta=0.122 ; \quad \mathrm{SE}=0.049)$ and mental health status ( $\beta=0.254$; SE $=0.046)$ predicted the global QOL represented by SWL scores (Fig. 1). The measurement loadings for PA and Self-Efficacy factors are moderately high (range $0.454-0.652)$ and highly significant $(p<0.001)$. The majority of the reported regression coefficients were significant at the 0.001 level, except PHS-SWL $(p=0.013)$.

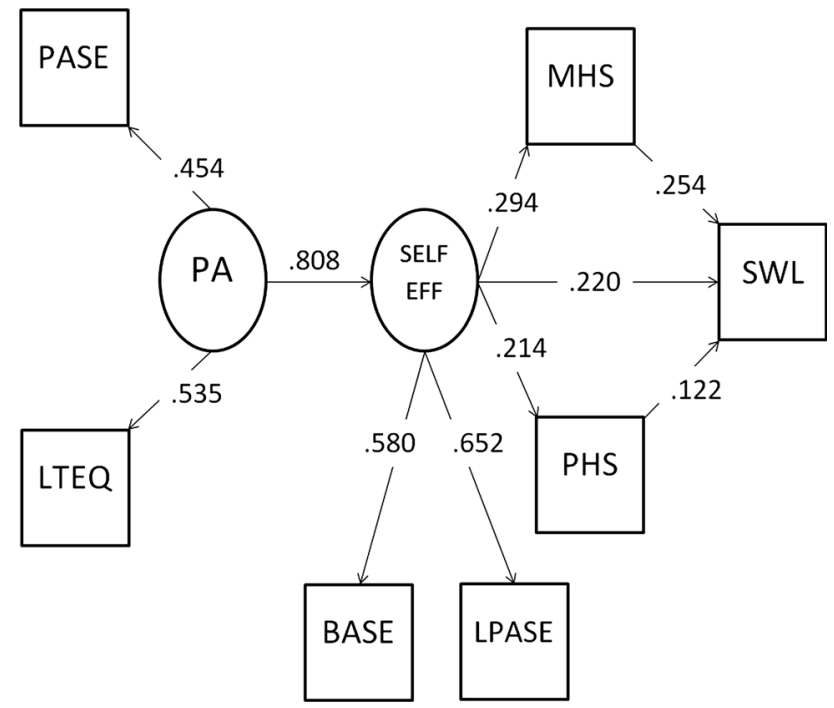

Fig. 1 Social cognitive model of the PA-QOL relationship

The model explained $17.6 \%$ of the variance in the QOL measured using the Satisfaction with Life scale.

Therefore, the social-cognitive model fits our data and appears to be applicable to older Czech adults, albeit with different emphases than for older US adults. Notably, compared to the US studies (McAuley et al. 2006, 2008; Motl and McAuley 2010), there seemed to be a larger direct effect of PA on self-efficacy and smaller mediating effect of health status in the self-efficacy-QOL relationship (Table 5).

\section{Discussion}

We examined the PA-QOL social-cognitive model as proposed by McAuley (McAuley et al. 2006, 2008) in the Czech cultural context and found that it fit the data obtained from the sample of older Czech adults relatively well. The increased participation in PA was associated with 
Table 5 Comparison of the observed effects with US studies

\begin{tabular}{lllll}
\hline & $\begin{array}{l}\text { Current study } \\
\beta(\mathrm{SE})\end{array}$ & $\begin{array}{l}\text { McAuley } \\
\text { et al. }(2006) \\
(\beta)\end{array}$ & $\begin{array}{l}\text { McAuley } \\
\text { et al. }(2008) \\
(\beta)\end{array}$ & $\begin{array}{l}\text { Motl and } \\
\text { McAuley (2010) } \\
(\beta)\end{array}$ \\
\hline PASE & $0.81(0.10)$ & 0.66 & 0.31 & 0.36 \\
SE-MHS & $0.29(0.05)$ & 0.32 & 0.24 & - \\
SE-PHS & $0.21(0.07)$ & 0.55 & 0.43 & - \\
SE-SWL & $0.22(0.06)$ & - & - & 0.19 \\
MHS-SWL & $0.25(0.05)$ & 0.41 & 0.37 & - \\
PHS-SWL & $0.12(0.05)$ & 0.42 & 0.38 & - \\
\hline
\end{tabular}

greater self-efficacy, which predicted better mental and physical health status. In turn, PA self-efficacy and physical and mental health status were positively related to global QOL, represented by the respondents' satisfaction with life. As hypothesized by the social cognitive theory (Bandura 1997), mastery experience with PA helps older people feel physically more in control of their body, which may translate to more positive evaluations of their health and also directly influence their satisfaction with life. Our results suggested that McAuley's social-cognitive model is plausible and has applicability within the Czech cultural context, although compared to the results obtained in the US samples (McAuley et al. 2006, 2008), the model fit was worse and the configuration of the parameters was different.

The results corroborated the importance of social-cognitive factors, namely, self-efficacy, in mediating PA-QOL relationships also in non-Western populations. Regarding the PA self-efficacy portion of the model, we found that participation in PA is positively associated with older adults' feelings of physical efficacy. This effect has been linked, for the most part, to the mastery experience with PA, although it has been argued that participation in PA influences PA self-efficacy through social influences, such as those obtained in social support for PA or through vicarious experience with PA. Thus, physically active older adults may feel more efficacious not only because they directly participate in PA but also because they tend to meet other physically active people who represent models of PA and provide additional support and encouragement (McAuley et al. 2003; Warner et al. 2011).

Compared to the US studies, participation in PA appeared to have a stronger association with PA self-efficacy in our sample. This finding suggested that PA selfefficacy in our respondents may stem even more from mastery experience with PA than from other hypothesized sources of self-efficacy, such as social support or vicarious experience. Previous studies have found that older Czech adults tend to be rather individualistic, participating for the most part in habitual work-related PA and avoiding participating in group and leisure PA (Mudrak et al. 2012;
Vohralikova and Rabusic 2004; Zavazalova 2001). Additionally, Czech discourse related to aging does not emphasize PA to a similar extent as observed in Western countries (Bauman et al. 2008). Compared to older Western adults, older Czech adults who have not been physically active in the past may have less access to other sources of PA self-efficacy because they may lack opportunities to obtain social support and encouragement toward PA from their peers, as well as appropriate models providing vicarious experience of PA in their age group.

Regarding the self-efficacy-QOL portion of the model, we found a positive relationship between PA self-efficacy and the physical and mental health as well as the global QOL of older Czech adults. Several mechanisms for explaining this relationship have been hypothesized. For example, people with high self-efficacy experience less health-related stress (Kreitler et al. 2007). Higher self-efficacy has been found to be associated with positive emotions and optimism (Karademas 2006), which may also partially explain the positive impact of self-efficacy on the physical and mental health status and satisfaction with life. McAuley et al. (2008) suggested that affective responses, perceived stress, self-esteem, and depression may play roles in the self-efficacy-HRQOL-QOL relationship.

However, it seems that health status has a weaker mediating effect on the self-efficacy-QOL relationship in our sample than in the studies on older US adults (McAuley et al. 2006, 2008). A plausible explanation for this observation may be that, compared to older Western adults, older people from post-communist countries generally live in worse socioeconomic conditions, adhere to behavioral norms that are less beneficial for their health, and perceive that they have less control over their health (Bobak et al. 2000; Carlson 1998, 2004; Dragomirecka et al. 2008; Eikemo et al. 2008; Laaksonen et al. 2001; Vuorisalmi et al. 2008). Bandura (1997) hypothesized that self-efficacy positively affects various aspects of life, including health, by facilitating "the exercise of control." In this way, people with high PA self-efficacy have an increased perception of themselves as agents of their own health, which allows them to actively engage in positive 
health-related behavior. However, PA self-efficacy might be less effective in older adults from post-communist countries, including the Czech Republic, as they seem to have (and perceive themselves to have) fewer opportunities to exercise their agency and positively influence their health by their own activity. The weaker mediating effect of health status may also be partially a result of the type of PA in which the older Czech adults participate. It has been argued that older Czech adults participate in little leisure PA, preferring to participate in work-related PA (Laaksonen et al. 2001; Mudrak et al. 2012; Vohralikova and Rabusic 2004). We may hypothesize that this type of activity is accompanied by a focus on benefits of PA other than health (i.e., economic), resulting in PA self-efficacy contributing less to a positive evaluation of one's health status.

There are several limitations in our study. Most importantly, the study employed a cross-sectional design that limits causal interpretations of the proposed relationships. Although the theoretical background prompts us to consider the proposed direction of causality valid, we may presume that the relationships proposed in the model are bidirectional, i.e., PA self-efficacy also influences participation in PA and health status affects both PA and PA selfefficacy. Future experimental data are needed to support the direction and causality of proposed relationships. Our sample should not be considered to represent the general Czech population of older adults because the study included, for the most part, well-educated older people who were predominantly women. However, because we did not aim to provide the descriptive characteristics of the general population of older Czech adults in our analysis but focused on exploring the process of PA-QOL relationship, we believed that the sample provided sufficient heterogeneity to examine this process. Moreover, other studies of the social-cognitive PA-QOL model conducted in the US context used similarly non-representative samples, such as older women (McAuley et al. 2006, 2008), communitydwelling older adults (predominantly white women) (White et al. 2009), or adults with multiple sclerosis (Motl and McAuley 2010). In this context, McAuley et al. (2008) presupposed certain universality of the proposed relationships and found only little impact of demographic variables, such as education, income, age, or race, on the model. The results of our study supported this presupposition. Regarding other limitations, we included only two indicators per construct in the SEM model, which limits the reliability considerations regarding the latent scores of the corresponding construct. The fact that we measured PA using self-report questionnaires presents a limitation to our study, although this method of assessing PA has been well established and frequently used in other studies with cognitively intact older adults.
Considering the practical implications of our results, the tested model suggested a series of relationships between variables, several of which (PA and PA self-efficacy, above all) are partially modifiable and should be targeted to improve the quality of life of older adults. PA should become an important concern of public health programs in countries where the trend toward "active aging" has emerged only recently, such as in post-communist countries in general and in the Czech Republic in particular (Bauman et al. 2008). Such PA interventions should focus on the development of PA self-efficacy as an important predictor of future PA and should recognize that reduced self-efficacy may lead to decreases both in PA participation and in the QOL of older adults (Warner et al. 2011; Elavsky et al. 2005). The interventions should include a focus on life-long participation in PA because the most efficient method of developing self-efficacy is mastery experience with activity, and PA self-efficacy of older adults may stem from their PA participation at a younger age (Bandura 1997). Furthermore, social support and models of physically active behavior should be present to further increase PA self-efficacy in older people. Additionally, leisure PA focused on health benefits should be an important component of the PA interventions because this type of PA seems to be underdeveloped in older adults from the Czech Republic and in other post-communist countries, and an intervention may provide an important positive influence on their health-related and global QOL.

To conclude, the applied SEM analysis allowed us to control measurement error and to consider the relationship between PA and global QOL. It also helped us to understand better the mediating role of self-efficacy and health status in the PA-QOL relationship. We confirmed the presupposed role of PA self-efficacy and the physical and mental health status in the PA-QOL relationship, although we observed, compared to US studies, a stronger effect of PA on PA self-efficacy and a weaker mediating effect of health status in self-efficacy-QOL relationship. In this way, our findings supported the validity of the social-cognitive PA-QOL model for use in non-Western cultural contexts, specifically in the context of the Czech Republic, providing foundation for further experimental studies testing proposed causal mechanisms.

Acknowledgments The study was supported by research Grant MSM 0021620864 from MSMT CR and was written in the Framework of the Scientific Branch Development Programme UK FTVS n. 39 Social-Sciences Aspects of Human Movement Studies.

\section{References}

Bandura A (1997) Self-efficacy. The exercise of control. Freeman, New York 
Bauman A, Schoeppe S, Lewicka M (2008) Review of best practice in interventions to promote physical activity in developing countries. WHO, Geneva

Bobak M, Pikhart H, Rose R, Hertzman C, Marmot M (2000) Socioeconomic factors, material inequalities, and perceived control in self-rated health: cross-sectional data from seven post-communist countries. Soc Sci Med 51:1343-1350

Bollen KA (1989) Structural equations with latent variables. Wiley, New York

Browne MW, Cudeck R (1993) Alternative ways of assessing model fit. In: Bollen KA, Long JS (eds) Testing structural equation models. Sage, Newbury Park, pp 136-162

Carlson P (1998) Self-perceived health in East and West Europe: another European health divide. Soc Sci Med 45:1355-1366

Carlson P (2004) The European health divide: a matter of financial or social capital. Soc Sci Med 59:1985-1992

Czech statistical office (2011) Seniori v CR 2011[Seniors in CR 2010]. Prague, Czech statistical office http://www.czso.cz/csu/ 2010edicniplan.nsf/publ/1417-10-nepravidelne_2010

Diener E, Emmons R, Larsen R, Griffin S (1985) The satisfaction with life scale. J Pers Assess 49:71-75

Dragomirecka E, Bartonova J, Eiseman M, Kalfoss M, Kilian R, Martiny K, von Steinbuchel N, Schmidt S (2008) Demographic and psychosocial correlates of quality of life in the elderly from a cross-cultural perspective. Clin Psychol Psychother 15:193-204

Eikemo T, Bambra C, Judge K, Ringdal K (2008) Welfare state regimes and differences in self-perceived health in Europe: a multilevel analysis. Soc Sci Med 66:2281-2295

Elavsky S, McAuley E (2007) Physical activity and mental health outcomes during menopause: a randomized controlled trial. Ann Behav Med 33:132-142

Elavsky S, McAuley E, Motl RW, Konopack JF, Marquez DX, Hu L, Diener E (2005) Physical activity enhances long-term quality of life in older adults: efficacy, esteem, and affective influences. Ann Behav Med 30:138-145

Elavsky S, Mudrak J, Slepicka P (2012) Physical activity and social cognitive influences on quality of life in Czech and American older adults. Czech positive psychology conference, Book of abstracts. Brno, Masaryk University, pp 85-86

Fox KR (1999) The influence of physical activity on mental wellbeing. Public Health Nutr 2:411-418

Godin G, Shephard RJ (1985) A simple method to assess exercise behavior in the community. Can J Appl Sport Sci 10:141-146

Hasmanova Marhankova J (2010) Konstruovani predstav aktivniho starnuti $\mathrm{v}$ centrech pro seniory [Construction of the Idea of Active Ageing in Centres for Seniors]. Sociol Cas 46:211-234

Havighurst RJ (1961) Successful aging. Gerontologist 1:8-13

Hu L, Bentler PM (1999) Cutoff criteria for fit indices in covariance structure analysis: conventional versus new alternatives. Struct Equ Model 6:1-55

Karademas EC (2006) Self-efficacy, social support and well-being. The mediating role of optimism. Personal Individ Differ 40:1281-1290

Kliman AM, Rhodes R (2008) Do government brochures affect physical activity cognition? A pilot study of Canada's physical activity guide to healthy active living. Psychol Health Med 13:415-422

Kramer AF, Colcombe SJ, McAuley E, Eriksen KI, Scalf P, Jerome GJ, Marquez DX, Elavsky S, Webb AG (2003) Enhancing brain and cognitive function of older adults through fitness training. J Mol Neurosci 20:213-221

Kreitler S, Peleg D, Ehrenfeld M (2007) Stress, self-efficacy and quality of life in cancer patients. Psycho-Oncology 16:329-341

Laaksonen M, McAlister A, Laatikainen T, Drygas W, Morava E, Nussel E, Oganov R, Pardell H, Uhanov M, Puska P (2001) Do health behaviour and psychosocial risk factors explain the
European East-West gap in health status? Eur J Public Healt 11:65-73

Laurin D, Verreault R, Lindsay J, McPherson K, Rockwood K (2001) Physical activity and risk of cognitive impairment and dementia in elderly persons. Arch Neurol 58:498-504

Leveille SG, Guralnik JM, Ferrucci L, Langois JA (1999) Aging successfully until death in old age: opportunities for increasing active life expectancy. Am J Epidemiol 149:654-664

MacCallum RC, Browne MW, Sugawara HM (1996) Power analysis and determination of sample size for covariance structure modeling. Psychol Methods 1:130-149

Marsh HW, Hau KT, Wen Z (2004) In search of golden rules: comment on hypothesis testing approaches to setting cutoff values for fit indexes and dangers in overgeneralising $\mathrm{Hu} \&$ Bentler's (1999) findings. Struct Equ Model 11:320-341

McAuley E (1992) The role of efficacy cognitions in the prediction of exercise behavior in middle-aged adults. J Behav Med 15:65-88

McAuley E, Morris KS (2007) Advances in physical activity and mental health: quality of life. Am J Lifestyle Med 1:389-396

McAuley E, Jerome GJ, Marquez DX, Elavsky S, Blissmer B (2003) Exercise self-efficacy in older adults: social, affective, and behavioral influences. Ann Behav Med 25:1-7

McAuley E, Konopack JF, Motl RW, Morris KS, Doerksen SE, Rosengren KR (2006) Physical activity and quality of life in older adults: influence of health status and self-efficacy. Ann Behav Med 31:99-103

McAuley E, Doerksen SE, Morris KS, Motl RW, Hu L, Wojcicki TR, White S, Rosengren KR (2008) Pathways from physical activity to quality of life in older women. Ann Behav Med 36:13-20

McAuley E, Mullen SP, Szabo AN, White SM, Wójcicki TR, Mailey EL, Kramer AF (2011) Self-regulatory processes and exercise adherence in older adults: executive function and self-efficacy effects. Am J Prev Med 41:284-290

Motl RW, McAuley E (2010) Physical activity, disability, and quality of life in older adults. Phys Med Rehabil Clin N Am 21:299-308

Mudrak J, Slepicka P, Elavsky S (2012) Physical activity and its social-cognitive correlates in Czech and American older adults. Czech Kinanthropology 16:49-63

Nelson ME, Rejeski J, Blair SN, Duncan PW, Judge JJ, King AC, Macera CA, Castaneda-Sceppa C (2007) Physical activity and public health in older adults: recommendation from the American College of Sports and Medicine and American Heart Association. Med Sci Sports Exerc 39:1435-1445

Netz Y, Becker JB, Wu M (2005) Physical activity and psychological well-being in advanced age: a Meta-analysis of intervention studies. Psychol Aging 20:272-284

Paterson DH, Warburton DE (2010) Review Physical activity and functional limitations in older adults: a systematic review related to Canada's Physical Activity Guidelines. Int J Behav Nutr Phys Act 7:1-22

Pelcova J, Vasickova J, Fromel K, Nykodym J (2008) Vliv demografických faktorů na pohybovou aktivitu a sezení obyvatel České republiky ve věku 55 až 69 let. Telesna kultura 2:109-119

Development Core Team R (2014) R: A language and environment for statistical computing. R Foundation for Statistical Computing, Vienna

Rabusic L (1998) The poverty of the Czech elderly — myth or reality? Sociol Cas 6:5-24

Rejeski JW, Mihalko SL (2001) Physical activity and quality of life in older adults. J Gerontol A Biol 56:23-35

Rosseel Y (2012) lavaan: an R package for structural equation modeling. J Stat Softw 48:1-36

Rowe JW, Kahn RL (1997) Successful aging. In: Dychtwald K (ed) Healthy aging: challenges and solutions. Aspen, Gaithersburg, pp 27-40 
Ruuskanen JM, Ruoppila I (1995) Physical activity and psychological well-being among people aged 65 to 84 years. Age Ageing 24:292-296

Spacek O (2009) Pohybove aktivity a sportovani verejnosti pred rokem 1989 a v soucasnosti [Public physical activity and sport before the year 1989 and now]. Ceska kinantropologie. 13:67-74

University Masaryk (2011) Komplexni evaluace vybranych vzdelavacich aktivit University tretiho veku ze strany cílové skupiny [A complex evaluation of selected educational activities of the University of the third age from the perspective of the participants]. Masaryk University, Brno

U.S. Department of Health and Human Services (2008) Physical Activity Guidelines for Americans. ODPHP Publication No. U0036

Vohralikova L, Rabusic L (2004) Cesti seniori vcera, dnes a zítra [Czech seniors yesterday, today, and tomorrow]. VUPSV, Brno

Vuorisalmi M, Pietila I, Pohjolainen P, Jylha M (2008) Comparison of self-rated health in older people of St Petersburg, Russia, and Tampere, Finland: how sensitive is SRH to cross-cultural factors? Eur J Ageing 5:327-334
Ware J, Kosinski M, Keller S (1996) A 12-item short-form health survey: construction of scales and preliminary tests of reliability and validity. Med Care 34:220-233

Warner LM, Schutz B, Knittle K, Ziegelmann JP, Wurm S (2011) Sources of perceived self-efficacy as predictors of physical activity in older adults. Appl Psychol Health Wellbeing 3:172-192

Washburn RA, Smith KW, Jette AM, Janney CA (1993) The physical activity scale for the elderly (PASE): development and evaluation. J Clin Epidemiol 46:153-162

Washburn RA, McAuley E, Katula J, Mihalko SL, Boileau RA (1999) The physical activity scale for the elderly (PASE): evidence for validity. J Clin Epidemiol 52:643-651

White SM, Wojcicki TR, McAuley E (2009) Physical activity and quality of life in community dwelling older adults. Health Qual Life Outcomes 7:1-7

Zavazalova H (2001) Vybrane kapitoly ze socialni gerontologie [Selected chapters from social gerontology]. Karolinum, Prague 